\title{
Correction to: Evaluating representational systems in artificial intelligence
}

\author{
John Licato ${ }^{1}$ • Zhitian Zhang ${ }^{2}$
}

Published online: 8 January 2018

(C) Springer Science+Business Media B.V., part of Springer Nature 2018

\section{Correction to: Artif Intell Rev https://doi.org/10.1007/s10462-017-9598-7}

In the original publication, the first paragraph of introduction section was published incorrectly. The corrected text was given in this correction.

Even before Rodney Brooks famously argued that "Elephants Don't Play Chess" (Brooks 1990), the question of how important explicit representations are to engineering intelligent systems has been a hotly debated point amongst researchers in AI and AI-related areas. These debates often come in the form of dichotomies, many of which are now familiar: localist versus distributed (Hinton et al. 1986), symbolic versus connectionist (Bringsjord 1991; Holyoak and Hummel 2000), explicit versus implicit (Sun 2002), declarative versus procedural (Winograd 1975; Willingham et al. 1989), system II versus system I (Kahneman 2011), and so on.

The original article has been corrected.

The original article can be found online at https://doi.org/10.1007/s10462-017-9598-7.

John Licato

licato@usf.edu

Zhitian Zhang

zhang820@purdue.edu

1 University of South Florida, Tampa, FL, USA

2 Purdue University, Fort Wayne, Fort Wayne, IN, USA 